\title{
Career orientation, development and evolution based on personal skills and aptitudes
}

\author{
Bianca Buta $^{1 *}$ \\ ${ }^{1}$ Lucian Blaga University of Sibiu, Bld. Victoriei 10, Sibiu, 550024, Romania
}

\begin{abstract}
This paper aims to bring forward the importance of the implementation of personal development and evolution programs within the educational systems. Combined with coaching techniques that help establish emotional balance and achieve positive changes with long-term effects, these programs are meant to bring together the educational offer and demand and match them with the labor market requirements. In the context of aligning educational policies at European level, an innovative and futureoriented approach is needed, reflecting current trends without sacrificing traditional values, which focus on classical teaching methods, but combining them with modern educational techniques. The proposed theme meets the current needs of the younger generations by identifying through the Holland Test skills and attitudes that allow lifelong learning and by creating learning contexts tailored to the needs of students, connected to the ever-changing world. The aim of the research is to identify programs that lead to the activation of a person's potential to maximize their performance through various coaching techniques and professional development programs carried out in internships, as well as in customized programs carried out in several stages, which combines traditional teaching techniques with modern ones (online school, new technologies, skills development).
\end{abstract}

\section{The concept of "aptitudes" and their relationship to personal development}

Recognizing the role of education as a strategic factor for development, both at national and European and global level, it became of utmost importance to define coherent development policies. These must encourage the continuous adaptation of people and systems to ongoing challenges in all areas of society, where the pace of change, their amplitude, as well as the unpredictability of the problems facing humanity require the development and cultivation of skills and abilities.

In the conditions of an accentuated demographic decline, the reduction of school dropout, which has reached worrying levels and is increasing, has become crucial for the sustainable development of Romania, allowing the capitalization of the potential of each child. Identifying skills and capitalizing on them is very important from an early age to establish the educational and professional path of young people. In everyday life, skills for a particular field are indicated by high performance in that field.

*Corresponding author: bianca.alina.buta@gmail.com 
At a very general level, skills refer to success in a certain field of activity. However, this definition is incorrect, as a student might achieve good results in a certain object of study, while a colleague of the same age could have a poor performance. This shouldn't mean that it would be a question of a superior aptitude of the former, if a simple analysis shows that he is additionally prepared for that discipline, or that his father has the same aptitudes. In this case, the superior performances in the respective field can be justified. Thus, one of the fundamental problems in defining skills appears: the relationship between skills and abilities.

Even the definitions in specialized dictionaries are marked by some ambiguity. Ability is defined as a trait synonymous with skill, dexterity, dexterity, dexterity, skill, highlighting the ease, speed, superior quality and precision with which man performs certain activities, involving self-organization appropriate to the task, flexible, efficient adaptation. It is frequently reported in the case of muscular, manual actions, thus having the meaning of method, working model or behavior applicable to concrete tasks. It is also noticeable in cognitive tasks. Ability is not to be confused with skill (...) and is not reduced to knowledge, as it is a condition for the optimal training and use, in new situations, of skills and knowledge. [1], while aptitude represents an attribute or system of attributes of the subject, mediating success in an activity; the ability to act and achieve performance; factor of the person who facilitates knowledge, practice, technical and artistic elaborations, communication [1] or a natural and acquired disposition to perform certain tasks [2].

\section{Competences in educational context: pedagogy through competences}

In recent decades, many phenomena and processes indicate that we are in a period of profound transformations that define the transition from industrial society to the knowledge society. These transformations consist, first, in a paradigm shift in terms of education. New theories and currents bring to the fore the theme of competencies, in their multiple forms: general or specific, professional or transversal, basic or key, etc. - a topic of fundamental importance, which has even led to the emergence of a 'competence-based pedagogy'.

The term "competence" has its origins in psychology and psycholinguistics (N. Chomsky), it was taken over at the end of the twentieth century in the field of professional qualifications, and in pedagogy, and the concept was introduced by J. Piaget and L. D'Hainaut. Briefly defined as "the proven ability to select, combine and use appropriately knowledge, skills and other acquisitions consisting of values and attitudes, for the successful resolution of a certain category of work or learning situations, as well as for professional development or personal in conditions of effectiveness and efficiency " (Romanian Academy, 2012). The term has, in reality, much deeper meanings, it being a genetic potential of the human spirit ("the ability to act effectively in a certain situation") [3].

Remy Chauvin (1975) distinguishes between the creative child and the talented child. Referring to these two concepts, Americans consider that a gifted child is the one who performs in all school subjects, while the talented child is the one who has outstanding results in a smaller number of disciplines or even just one. However, there is a significant difference between the gifted and the gifted child: the gifted child is related to IQ, while the talented child is related to creativity, as there may be very intelligent and less creative children, but vice versa.

In general, in the definition of intellectual endowment there are several ideas:

- The existence of high skills in a specific field or several fields;

- These skills may manifest themselves explicitly or may remain dormant;

- Hereditary factors are important in their determination;

- Adequate environmental conditions are needed to be able to assert itself. 
De Ketele (1996) defined competence as an ordered set of abilities that is exercised over contents in a certain category of situations to solve the problems limited to that situational field [4]. This approach highlights the three components of a competence: content, capacity and situation.

As an item on the Lisbon agenda, the Council of Europe has recognized education, training and employment as an integral part of the economic and social policies needed to transform Europe's economy into the most dynamic knowledge-based economy. Initially, the focus was on disadvantaged groups, those with specific needs, school dropout and adult education, in this context the term "competence" referring to achieving "a degree of integration between capabilities and the broader social goals it needs".

In the new context favored by the paradigm shift in education, combined with the support provided in this field by the European Union, there has been an increasing interest given to the direct relationship between skills and professional objectives, implicitly employability.

The key competences aim at lifelong learning and are not limited, therefore, to the educational process, the Recommendation stating that they must be acquired by young people at the end of compulsory education and training, as well as by adults, throughout lifelong learning life, through a process of developing and updating skills.

The competency-based educational process is therefore a set of techniques aimed at developing competencies. It proves its efficiency and effectiveness in combined contexts (formal, non-formal, informal) and if it cumulatively meets several conditions:

- The competencies that the student must demonstrate at the end of each school year, at the end of a school year, and at the end of compulsory schooling are clearly defined. Thus, the teacher's activity will focus less on design and more on the organization and coordination of learning, as well as on providing feedback, and as far as the student is concerned, he must prove that he knows how to use, apply, what he learns.

- Competence pedagogy must give meaning to learning, facilitating real learning contexts, through which the student is motivated that everything he learns is useful to him. For this, however, there are no longer enough lists of mono-disciplinary contents, being necessary and mandatory interdisciplinary, creative and innovative approaches.

- Competences should not be seen as a combination of knowledge, skills and other acquisitions, but because of their combined application for solving situations.

\section{The Holland test- psychological evaluation of professional interests applied on high school students}

The Holland test is one of the most widely used tools for the psychological assessment of professional interests. It is used in various forms, all over the world. The questionnaire is based on the theory of occupational interests of the American psychologist John Holland. He pointed out that people resonate more or less with work environments depending on each person's personality. Thus, according to his theory, we choose one career or another depending on six personality factors, exemplified in Table 1.

Table 1. Personality factors.

\begin{tabular}{|l|l|}
\hline Artistic people & $\begin{array}{l}\text { - Usually creative, open, inventive, original, perceptive, sensitive, } \\
\text { independent and emotional. } \\
\text { - Do not like structure and rules, like tasks involving people or } \\
\text { physical skills, and are more likely to express their emotions than } \\
\text { others. } \\
\text { - Like to think, organize and understand artistic and cultural areas. } \\
\text { - Like to work with IDEAS and THINGS. }\end{array}$ \\
\hline
\end{tabular}




\begin{tabular}{|l|l|}
\hline Conventional people & $\begin{array}{l}\text { - Like rules and regulations and emphasize self-control. } \\
\text { - They like structure and order, and dislike unstructured or unclear } \\
\text { work and interpersonal situations. } \\
\text { - They place value on reputation, power, or status. They like to work } \\
\text { with DATA. }\end{array}$ \\
\hline Enterprising people & $\begin{array}{l}\text { - Good talkers, use this skill to lead or persuade others. } \\
\text { - Value reputation, power, money and status } \\
\text { - They like to work with PEOPLE and DATA }\end{array}$ \\
\hline Investigative people & $\begin{array}{l}\text { - Like to think and observe rather than act, to organize and } \\
\text { understand information rather than to persuade } \\
\text { - Tend to prefer individual rather than people oriented activities. } \\
\text { - They like to work with DATA }\end{array}$ \\
\hline Realistic people & $\begin{array}{l}\text { Are usually assertive and competitive, and are interested in } \\
\text { activities requiring motor coordination, skill and strength. } \\
\text { - Like concrete approaches to problem solving, rather than abstract } \\
\text { theory. } \\
\text { - Tend to be interested in scientific or mechanical rather than } \\
\text { cultural and aesthetic areas. } \\
\text { - Like to work with THINGS. }\end{array}$ \\
\hline $\begin{array}{l}\text { - Seem to satisfy their needs in teaching or helping situations. } \\
\text { - Are drawn more to seek close relationships with other people and } \\
\text { are less apt to want to be really intellectual or physical. } \\
\text { - Like to work with PEOPLE. }\end{array}$ \\
\hline Social people
\end{tabular}

In order to test the correlation between aptitudes and a possible choice of career, the Holland test was distributed during an internship for high school students, which took place at the company Marquardt Romania, in 2021.

Well known at local and national level for their involvement in the community, Marquardt Romania is an automotive company specialized in mechatronics. The Sibiu branch opened in 2006 and currently employs over 2500 people from Sibiu and the surrounding area. Ever since the beginning of their operations in Romania, the company was involved in many educational projects, including the national implementation of vocational school in dual system (high school) or the dual system higher education. Throughout time, a successful partnership was also built with Samuel von Brukenthal National College, a top educational institution from Sibiu and among the best rated in the country. Within the frame of this partnership, selected students of this college are offered the opportunity to take part in a one-week internship in the company. During this time, they become familiar with the business environment, as they rotate between the departments and participate to presentations on the activity and main tasks. The internship is also a good opportunity for them to acquire new competences and to receive basic career guidance for the future. One of the stages of the internship is taking the Holland test and receiving the result interpretation.

The test consisted of 120 questions and ran for 45 minutes; the target group was of 38 students - 11th grade, with the purpose of psychological evaluation of professional interests. The students were split into four groups, for easier management and supervision.

The results of the test demonstrated an unequal distribution of the determinants of the participants' personality, with a higher share of investigative and entrepreneurial styles. Given the theoretical profile of the high school where the participants study, the results confirm the close link between personality, skills and individual educational path. From 38 eligible answers, 13 students (34\%) showed dominant investigative personality traits, suggesting possible careers matching their personality, such as IT programmer, economist, management consultant, chemist, biologist, physicist, pharmacist, psychologist, geographer etc. Conventional personalities resulted for seven students (19\% of the total), indicating suitable professions such as accountant, financial analyst, librarian, telecommunications 
operator, cashier or computer operator. Dominant enterprising personality traits were demonstrated by seven students (19\%), best suited for jobs such as management, law, public relations, insurances, tourism or marketing and publicity. Social (13\%), Artistic (13\%) and Realistic (1\%) personalities are at the bottom of list, but this might also be caused by the profile of the studies, indicating once more that the personality is a determining factor in the choice of career or professional path. A high proportion of answers in these categories, compared with the specificity of the studies, would be a clear indicator that the personality was not considered when choosing the profile of the high school.

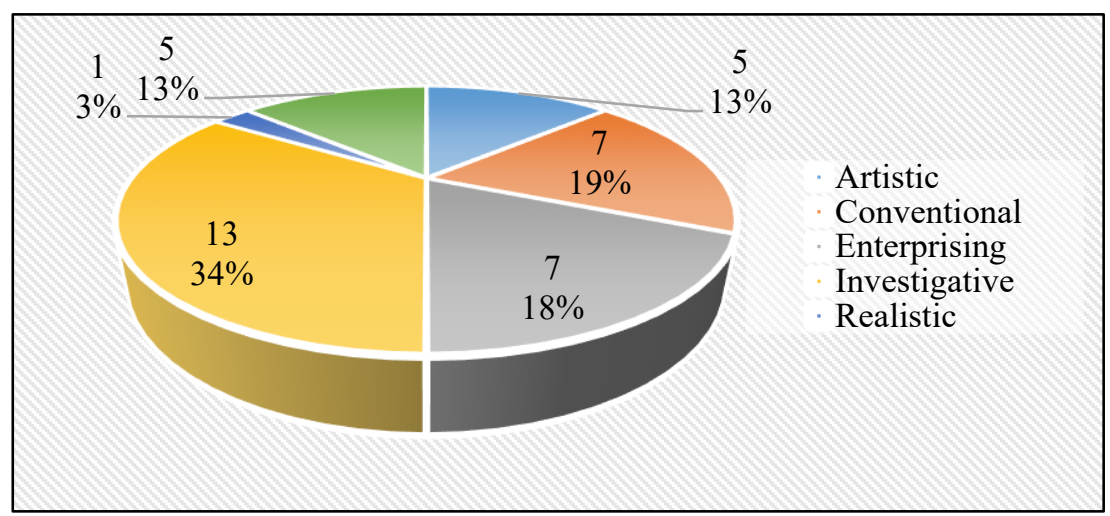

Fig. 1. Distribution of the results.

\section{Perspectives of modernization of the educational system through professional development and coaching programs}

The ever-changing nature of the business environment, the workforce and the crises in the economic, technological, military, political, health fields have led organizations to recognize the increasingly important role of continuing vocational training and development. Many companies recognize that their long-term viability and productive capacity are based on the quality of human resources employed. Thus, vocational training is seen as a nodal element not only to improve individual effectiveness, but also to enhance organizational efficiency by meeting various needs of both the individual and the organization.

In the current national context, there is a lack of a stable channel for transferring information from the education system to the labor market and vice versa, leading to imbalances between labor supply and demand.

There is also a need for large-scale implementation of methods to identify the skills, aptitudes and inclinations of young people and their subsequent orientation towards occupations that fit their features on the one hand and meet the requirements of the labor market on the other. Although there is a framework program for career counseling and guidance, it has not produced its effects and, consequently, the need for retraining and readjustment to the entrepreneurial environment arises during the professional life. For example, people who have technical skills but have not been properly guided to the right professions or, for various reasons, work in other fields, are aware of the need for this retraining even after a longer time. In order to avoid these situations, it is necessary to have programs for the identification and development of skills, which facilitate the decision of young people to pursue a career appropriate to their personal inclinations.

The recent health crisis has brought to the attention of the whole world the urgent need for digitalization both in the entrepreneurial environment and in education. The impossibility of carrying out the education process in a classic way, through the physical presence of 
teachers and students, accelerated the lacunar, forced and incomplete implementation of some technologies meant to facilitate this learning process. From the oral teacher-student interactions to the development of the assessment process, technologies have been identified to allow their development at a distance, with minimal impact on the quality of the learning process. However, given the forced circumstances in which this new system was implemented, there is a negative psychological impact of the lack of direct interaction.

Once personal skills and inclinations are identified, they can be encouraged and developed through coaching sessions adapted to age and personal needs, which also include basic concepts related to prevention and health and safety in the workplace.

The emotional development of the individual is also required; because according to various coaching studies, emotions drive people and people bring performance. Another important role is also played by the development of communication and leadership skills, as based on the communication created between 2 or more people, a constructive relationship can be developed that generates devotion and leads to increasing performance and achieving the proposed results.

Given the need for adaptable and flexible workforce, organizations have begun to identify the key competencies they want to establish and develop in order to increase organizational effectiveness.

\section{Conclusions}

Starting from the current situation, a need to identify personal development and evolution programs combined with coaching techniques to be applied throughout the school, academic and even professional activity becomes obvious.

The permanent issue of school abandon in Romania is also a topic that might be improved by ensuring constant career guidance during the school years. An early identification of aptitudes could return on the long-term professional success, as it can steer the academic and career choices towards fields for which the individual is naturally inclined.

From an employability point of view, coherent educational policies that take into account the personal skills and aptitudes could lead to better correlation between the demand and the offer for workforce. An educational process that is adjusted to the personality of the individual can produce future employees who are motivated, passionate and willing to improve and perfect their knowledge.

\section{References}

1. P. Neveanu-Popescu, Dicţionar de Psihologie (Albatros, Bucharest, 1978)

2. N. Sillamy, Larousse. Dicționar de psihologie (Univers Enciclopedic, Bucharest, 2000)

3. Ph. Perrenoud, The Key to Social Fields: Competencies of an Autonomous Actor, in Rychen, D. S. and Sagalnik, L. H. (dir.) Defining and Selecting Key Competencies. (Hogrefe \& Huber Publishers, Gottingen, 2001).

4. X. Roegiers, Une pédagogie de l'intégration. Compétences et intégration des acquis dans l'enseignement (De Boeck, Bruxelles, 2001) 